\title{
Pembelajaran PKN Dengan Paradigma Integratif Guna Pembentukan Karakter Siswa
}

\section{Veni Veronica Siregar ${ }^{1 *}$, Mugowim² $^{2}$ Jonata $^{3}$}

1,2,3 Jurusan Pendidikan Guru Madrasah Ibtidaiyah, Universitas Islam Negeri Sunan Kalijaga, Indonesia

\section{ART I CLE I N F O}

Article history:

Received March 09, 202

Revised April 15, 2021

Accepted June 10, 2021

Available online July 25, 2021

Kata Kunci:

PKn, Pradigma Integrasi, Karakter

Keywords:

Civics, Integration

Paradigm, Character

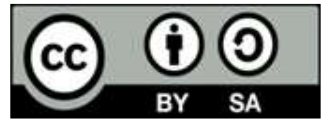

This is an open access article under the CC BY-SA license.

Copyright $\left({ }^{\circ} 2021\right.$ by Author. Published by Universitas Pendidikan Ganesha.

\begin{abstract}
A B S T R A K
Karakter menjadi permasalahan yang tidak pernah usai, misalnya saja pelecehan seksual, bullying dan korupsi yang meraja rela dinegeri kita, hal ini mencerminkan bahwa minimnya kualitas karakter bagi manusia. Pendidikan diharapkan mampu menjadi solusi dalam pembentukan. Tujuan penelitian ini menganalisis karakter apa saja yang dapat terbentuk dengan mengintegrasikan pembelajaran PKn. Jenis penelitian ini yaitu kualitatif yang bersifat penelitian lapangan (field research). Subjek penelitian ini berjumlah 9 orang guru. Pengambilan sampel sumber data dilakukan secara purposive. Metode yang digunakan untuk mengumpulkan data yaitu observasi, wawancara, serta dokumentasi. Instrument yang diguanakn untuk mengumpulkan data yaitu angket. Teknik yang digunakan untuk menganalsis data yaitu analisis dekriptif kualitatif. Prosedur penelitian ini mengunakan teknik analisis data yang berupa pengumpulan data, reduksi data, display data dan verifikasi data. Hasil penelitian yaitu pembelajaran PKn dengan mengintegrasikan nilai PKn bagi siswa dapat dikatakan berhasil dimana siswa memiliki krakter rasa toleransi, memiliki rasa persahabatan dan komunikasi serta siswa memiliki rasa cinta dan peduli terhadap tanah air. Implikasi penelitian ini yaitu pembelajaran PKn sangat cocok diberikan kepada siswa untuk membangun karakter siwa yang positif.
\end{abstract}

\section{A B S T R A C T}

Character is a never-ending problem; for example, sexual harassment, bullying, and corruption that are rampant in our country reflect the lack of character quality for humans. Education is expected to be a solution in the formation. The purpose of this study is to analyze what characters can be formed by integrating Civics learning. This type of research is qualitative field research (field research). The subjects of this study amounted to 9 teachers. A sampling of data sources is done purposively. The methods used to collect data are observation, interviews, and documentation. The instrument used to collect data is a questionnaire. The technique used to analyze the data is qualitative descriptive analysis. This research procedure uses data analysis techniques in data collection, data reduction, data display, and data verification. The study results, namely Civics learning by integrating Civics values for students, can be said to be successful where students have the character of a sense of tolerance, a sense of friendship and communication, and students have a sense of love and care for the homeland. This research implies that Civics learning is very suitable for students to build positive student characters.

\section{PENDAHULUAN}

Setiap dalam diri sesorang memiliki karakter yang berbeda-beda dan khas sehingga membedakan antara individu satu dengan yang lainnya. Karakter adalah cara berpikir dan berperilaku yang menjadi ciri khas tiap individu untuk hidup dan bekerjasama, baik dalam lingkup keluarga, masyarakat dan negara (Dalmeri et al., 2015; Lewis \& Ponzio, 2016). Individu yang berkarakter baik adalah individu yang bisa membuat keputusan dan siap mempertanggungjawabkan akibat dari keputusan yang dibuatnya (Erliani, 2017; Putrayasa, 2017). Karakter dapat di bentuk melalui aktivitas yang tidak hanya sebatas kegiatan materi pembelajaran, namun harus adanya kegiatan pembiasaan yang dilakukan (Marhayani, 2016; Zahro et al., 2017). Hal ini seharusnya dapat diterapkan disuatu sekolah yang disebut sebagai program didalam sekolah tersebut. Karakter yang terbentuk itu tidaklah instan tetapi memiliki proses dan tindakan nyata yang dilakukan (Baehaqi, 2020; Novianti, 2017). Melalui proses inilah cara-cara jitu dapat dihadirkan pihak sekolah guna untuk mebentuk karakter yang diharapkan (Birhan et al., 2021; Singh, 2019). Karakter memiliki peran yang penting bagi siswa dalam kehidupan bermasyarakat agar 
siswa mampu bersosialisasi dengan berbagai macam perbedaan, memiliki jiwa tangung jawab terhadap diri sendiri, serta mempersiapkan siswa untuk menghargai pihak lain (Budiwibowo, 2016; Nugrahani, 1386).

Namun, karakter menjadi sebuah permasalahan yang terus terjadi dan ada yang menjadi persoalan yang seakan tidak akan pernah usai (Pane \& Rina Patriana, 2016; Prasetyo et al., 2020). Krisis moral dan etika yang dialami bangsa kita saat ini sangatlah memprihatinkan. Keadaan ini menjadikan situasi menjadi lebih parah lagi, jika pemerintah tidak mengusahakan strategi dalaam jangka pendek dan panjang (Agnies zka Bates, 2019; Liang et al., 2021). Seperti yang kita ketahui bahwa kejujuran merupakan harta yang paling berharga dinegeri ini, bagaimana tidak akhir akhir ini korupsi semakin meraja lela dinegera kita seperti kasus korupsi bansos dana covid 19 pada wilayah jabotabek tahun 2020. Pada kasus ini menyeret nama menteri sisial RI nonaktif serta politikus PDI Juliari peter batubara di duga menerima uang sebesar 17 milyar dari dua paket dana bantuan bansos (Octavia, 2020). Selain itu ada juga kasus korupsi proyek hambalang pada tahun 2009 yaitu sebagai peroyek pembangunan pusat pelatihan olahraga tingkat nasional dengan anggaran mencapai 1,75 trililiun yang terletak di bogor. Dari kasus korupsi ini maka dapat kita lihat bahwa memiliki pengetahuan saja tidaklah cukup perlu adanya karakter kejujuran yang tertanam yang menjadi pondasi dalam kehidupan (Khoiri et al., 2017; Ramdan \& Fauziah, 2019; Suwartini, 2017).

Berdasarkan hasil observasi awal diperoleh informasi dari salah satu guru MI 01 Rejang Lebong, setelah proses penjelasan dalam materi pembelajaran dikelas guru menggabungkan berapa unsur pembelajaran yang telah dipelajari, misalnya saja dalam pembelajaran PKN menyatukan dengan ilmu sosial bagi siswa dan guru tidak hanya mengajarkan bela negara tetapi juga pembelajaran moral etika karakter bagi siswa dari pembelajaran PKN. Selain itu pihak sekolah sangat mendukung sekolah memberikan guru-guru pelatihan tentang integrasi pembelajaran yang diikut guru. Pembelajaran yang terjadi sudah semestinya memiliki timbal balik dari pembelajaran bukan hanya sebagai angka yang menjadi tolak ukur keberhasilan tetapi harus adanya aksi yang terjadi ketika siswa mendapatkan suatu pengetahuan baru (Pratama et al., 2021; Thoyyibah et al., 2019). Misalnya saja di MI 01 Rejang Lebong telah adanya timbal balik antara pembelajaran dan tindakan nyata yang dilakukan seperti guru memberikan tugas mengenai gotong royong maka siswa diperintahkan untuk melaksanakan gotong royong, tetapi masih ada siswa yang tidak melaksanakan gotong royong. Kegiatan seperti ini adalah salah satu Pendidikan sikap (Dewi et al., 2013; Supardi, 2010).

Pendidikan sikap adalah suatu kewajaran yang disebabkan oleh pilihan moral, perilaku dan sikap, orang-orang ini memiliki kualitas moral yang baik bahkan ketika tidak ada yang melihatnya (Dalmeri et al., 2015; Genc et al., 2018). Pendidikan karakter tidak hanya tentang perbuatan baik dan buruk, namun menanamkan kebiasaan berbuat baik dalam pembelajaran karakter agar siswa bisa mengetahui hal baik dan hal yang salah (Öztürk et al., 2020; Suryawati \& Osman, 2018). Selain itu siswa dapat memilih dengan bijaksana hal yang dilakukan dan siap menerima resiko, mengontrol diri sendiri, bekerja keras, serta memiliki rasa kemanusian (Ma et al., 2020; Maulida et al., 2020; Nordlöf et al., 2019). Pendidikan karakter pada hakikatnya adalah pendidikan nilai yang ada pada individu dimana nilai menjadi suatu kulitas individu (Baehaqi, 2020; Novianti, 2017). Hakikat pendidikan adalah upaya memanusiakan manusia menjadi manusiawi. Melalui pendidikan, potensi manusia akan tumbuh berkembang menjadi insan yang tertata pola pikirnya, termanifestasikan sikap dan tingkah laku baiknya (Pane \& Rina Patriana, 2016; Prasetyo et al., 2020). Pendidikan mengarahkan manusia dari sebelumnya tidak mengetahui banyak hal menjadi tahu banyak, sebelumnya berperilaku kurang baik menjadi berperilaku baik. Pendidikan menfasilitasi manusia menjadi dewasa, bertanggung jawab, jujur, beradab, dan berkarakter (Liang et al., 2021).

Penelitian sebelumnya yang dilakukan menyatakan bahwa guru dapat mengimplementasikan kurikulum 2013 dalam membentuk karakter siswa pada pemebelajaran tematik-integratif. Dalam penelitian ini guru mempunyai strategi dalam membentuk karakter siswa, yaitu dengan cara pembiasaan, keteladanan dan kedisiplinan yang dapat diterapkan oleh siswa (Agnies zka Bates, 2019; D. P. Ningsih \& Maulida, 2019). Penelitian sebelumnya juga menyatakan bahwa guru dapat mementuk karakter siswa dengan memberikan pembelajaran yang positif (Alsabahi et al., 2021; Muhtar \& Dallyono, 2020; Rosala \& Budiman, 2020). Temuan penelitian lainnya juga menyatakan bahwa penanaman nilai-nilai karakter melalui pembelajaran PPKn (Dewi et al., 2019; Suprihatin, 2017).

Tujuan penelitian ini menganalisis karakter apa saja yang dapat terbentuk dengan mengintegrasikan pembelajaran PKn. Peneliti perpandangan bahwa karakter yang terbentuk dapat melalui kebiasaan kebiasaan yang terjadi secara langsung sehingga ada kesambungan antara pemhaman teori didampingi dengan kegiatan pembiasaan yang dapat menunjang membantu dalam penanaman karakter siswa. Dalam pemeblajaran PKN banyak sekali pembelajaran yang dapat menjadikan siswa memiliki karakter yang baik tentu dalam hal menanamkan karateter terhadap peserta didik tidaklah mudah namu dapat dilakukan dengan kebiasaankebiasan yang baik, misalnya saja dengan kegiatan berdoa sewaktu memulai dan selesai pembelajaran, sholat bersama disekolah, menghargai teman, mencintai perbedaan, adil dalam b eteman, didalam pembelajaran PKn terdapat materi tentang pancasila dimana dalamnya mengandung nilai-nilai nasionalisme yang harus dimiliki individu (Ikhsan, 2017; Sriyanto et al., 2019). 


\section{METODE}

Di dalam penelitian ini, peneliti menggunakan jenis penelitian kualitatif yang bersifat penelitian lapangan (field research). Dalam penelitian subjek penelitian berjumlah 9 orang yang terdiri dari guru wali kelas III dan siswa kelas III. Penelitian ini adalah pradigma integrasi nilai untuk membentuk karakter siswa yang dalam hal ini adalah siswa kemudian dengan melalui mata pembelajaran pendidikan kewarganegaraan (PKn). Kemudian untuk mendapatkan informasi, metode yang digunakan untuk mengumpulkan data yaitu observasi, wawancara, serta dokumentasi. Observasi yang berkaitan dengan pengamatan yang meliputi kegiatan dalam proses pembelajaran yang berlangsung, dengan mengunakan semua alat indera. Penelitian ini mengunakan pendekatan secara langsung dengan guru, wawancara juga perlu dilakukan untuk mendapatkan informasi mengenai bagaimana pelaksanaan program pendidikan karakter, karakter apa saja yang dapat terbentuk melalui pradigma integratif dalam pembelajaran PKn. Wawancara diperlukan untuk menemukan informasi yang terkait dengan bagimana pradigma integritas pembelajaran PKn yang dilakukan oleh guru dalam upaya membentuk karakter siswa. Wawancara adalah suatu percakapan yang dilakukan untuk medapatkan suatu informasi yang diperlukan, wawancara dapat dilakukan baik dengan secara langsung atau tidak langsung yang dilakukan dua individu atau lebih, didalam wawancara ada perbedaan kedudukan dimana pihak pertama disebut sebagai penaya dan pihak kedua dapat dikatakan sebagai pihak informasi. Selain itu penelitian ini memerlukan referensi sebagai sumber pendukung dalam penulisan ini untuk menganalisi pembelajaran PKn dengan pradigma integratif dalam pembentukan karakter siswa. Teknik yang digunakan untuk menganalsis data yaitu analisis dekriptif kualitatif. Adapun prosedur penelitian ini mengunakan teknik analisis data yang berupa pengumpulan data, reduksi data, display data dan verifikasi data.

\section{HASIL DAN PEMBAHASAN}

\section{Hasil}

Berdasarkan hasil penelitian yang dilakukan didapatkan beberapa temuan mengenai paradigma integratif dalam pembelajaran PKn. Guru dalam pembelajaran PKn memberikan pembahasan materi gotong royong yang mencerminkan karakter bangsa, sehingga siswa dapat menerapkan gotong royong didalam kehidupan mereka tanpa melihat ras, suku, agama dan budaya. Disekolah siswa melaksanakan gotong royong setiap hari jumat yang dinamakan jum'at bersih dengan adanya kegiatan ini siswa dapat memiliki rasa kepedulian terhadap lingkungan, adanya kerjasama yang dilakukan melatih siswa untuk selalu membantu sesama. Dalam pembelajaran PKn guru melakukan penggabungan misalnya pembelajaran tentang pancasila maka guru menanamkan unsur kehidupan nyata bagi siswa, yaitu bagaimana cara menghargai perbedaan yang ada dilingkungan bahwa semuanya sama tidak membeda-bedakan antar individu maupun kelompok, dengan cara menerima pendapat dari orang lain sehingga siswa mampu menghargai teman satu kelas yang memiliki berbagai macam ragam bahasa dan agama dalam hal ini mendapatkan hasil bahwa siswa memiliki rasa saling menghargai dan meghormati. Dalam paradigma integratif upaya yang dilakukan guru dapat menghasilkan rasa empati bagi siswa yang dapat diterapkan didalam kehidupan nyata mereka, misalnya guru menggunakan media pembelajaran sebagai alat bantu dalam pembelajaran dengan memberikan video pembelajaran tentang bagaimana rasa cinta terhadap tanah air, bagaimana rasa saling menghormati, menghargai, menyayangi, saling tolong-menolong dari sebuah kisah perjuangan pahlawan terdahulu. Maka hasil yang diperoleh siswa akan memiliki rasa kepedulian terhadap siswa-siswi. Dengan begitu siswa memiliki rasa kepedulian yang dapat menjadikan siswa memiliki tempat dimasyarakat diterima dengan baik.

Guru memiliki beberapa faktor penghambat dimana siswa terpengaruh didalam lingkungan diluar sekolah serta teman sebaya menjadi faktor penghambat, karenakan masih ada beberapa siswa yang tidak dapat melaksanakan prilaku yang baik dimana siswa tersebut masih sering membully teman kelasnya serta belum memiliki rasa empati untuk saling membantu, hal ini dikarenakan lingkungan yang mempengaruhi siswa. Selain itu untuk mendukung kekurangan maka guru dan pihak sekolah memberikan fasilitas yang diperlukan selain fasilitas pihak sekolah mmberikan kegiatan setaip jumaat pagi yaitu kultum pagi dimana setiap acara tersebut siswa diberikan arahan nasehat oleh para guru. Berdasarkan hasil diatas maka dapat disimpulkan bahwa dapat dikatakan integrasi pembelajaran PKn sudah dapat membentuk karakter siswa misalnya saja siswa tidak memandang golongan ras suku mereka tetap berteman saling membantu saling mengasihi, serta didalam kehidupan nyata siswa dapat menerapkan nilai dari pembelajaran PKn dengan membantu sesama tanpa memandang agama. Hal ini dapat menunjukan bahwa terbentuknya karakter siswa yaitu toleransi, sahabat/komunikasi, cinta tanah air dan peduli soslial selain itu ada juga yang mempengaruhi faktor pendukung dan penghambat misalnya saja lingkungan teman sebaya bisa menjadi penghambat dan peran orang tua bekerja sama dalam sebuah tim sekolah, mempunyai fasilitas dan motivasi menjadi pendukung dari terbentuknya karakter siswa dengan mengintegrasikan pembelajaran PKn.

\section{Pembahasan}

Pendidikan nilai-nilai yang terdapat didalam pancasila dalam mata pelajaran kewarganegaraan terdapat hubungan yang signifikan antara global dan pancasila dikarenakan nilai pancasila dapat dianggap mamppu 
beradaptasi dengan perubahan jaman (Putri, 2018; Sudaryanti et al., 2015). Pendidikan Pancasila dan UUD 1945 dicakup dalam pengetahuan PKn yang didalamnya menyangkut semua aspek dalam kehidupan bernegara menciptakan manusia berkarakter dalam dinamika kehidupan, serta mewujudkan nilai dalam kehidupan seharihari (Buchori et al., 2017; Juneman et al., 2012). Dalam pembelajaran PKn ada empat pembahasan yaitu konsep nilai, moral dan norma. Nilai adalah suatu kualitas yang melekat yang ada didalam diri manusia dalam aspek kehidupan sebagai suatu aspek yang berharga serta bermanfaat (Mediatati \& Suryaningsih, 2017; Sakaningsih et al., 2014). Moral merupakan perilaku yang dilakukan individu yang tolak ukurnya kebaiakan didalam kehidupan sehari-hari (Safitri et al., 2019; Winther-Lindqvist, 2020). Norma merupakan petunjuk yang ada didalam kehidupan bernegara misalnya norma agama, hukum kesopanan, dan kesusilaan.

Nilai-nilai moral warga negara dalam mensosialisasikan dan menginternalisasikan nilai-nilai peserta didik, termasuk nilai-nilai Pancasila atau unsur budaya bangsa (Iannuccilli et al., 2021; Pebriana, 2017). Nilai yang terkandung didalam Pancasila secara individu dapat sebagai cermin dalam kehidupan sehari-hari yang terlaknasanakan dalam bertindak dan berikap (Inanna, 2013; Khaironi, 2017). Didalam pembelajaran langsung pendidikan karakter bangsa diintegrasikan ke dalam seluruh mata pembelajaran dengan pendekatan pembelajaran terpadu sehingga internalisasi nilai-nilai pembelajaran kepada peserta didik dapat dilakukan dapat dilakukan dalam seluruh kegiatan pembelajaran (Gönültaş et al., 2021; Panagopoulos et al., 2018). Disamping itu guru yang berperan sebagai barisan terdepan yang terlibat langsung dalam pembentukan karakter siswa tidak hanya mambu mencetak siswa yang memiliki pengetahuan tinggi tetapi siswa yang berkarakter (Farisia, 2016; Hafeez et al., 2020).

Nilai karakter religius mewujudkan keyakinan kepada Tuhan Yang Maha Esa dan diwujudkan dalam penerapan dokrin dan keyakinan agama serta perilaku menghargai perbedaan agama (Khoiri et al., 2017; Thoyyibah et al., 2019). Mempraktikkan sikap toleran terhadap pemeluk agama, pemeluk agama lain dan hidup rukun dengan pemeluk agama lain. Nilai religius ini mencakup tiga dimensi hubungan, yaitu hubungan individu dengan Tuhan, hubungan individu dengan sesama, hubungan individu dengan lingkungan (Cahyaningrum et al., 2017; Widodo, 2020). Hal ini menunjukkan nilai dari tokoh agama ini bertindak dalam cinta dan menjaga keutuhan ciptaanya. Nilai-nilai sub-agama meliputi cinta damai, tolenransi dan rasa hormat. Perbedaan keyakinan agama, keyakinan teguh, percaya diri, kesetraan antar pemeluk agama, anti bullying dan kekerasan, persahabatan, ketulusan, tidak ada paksaan, cinta lingkungan melindungi penjahat dan orang-orang yang terpinggirkan (Ghufron, 2010; Mustofa \& Syafi'ah, 2018).

Nilai kepribadian nasionalis adalah cara berpikir, berperilaku dan bersikap yang menunjukkan kesetiaan, kepedulian dan rasa hormat sangat mementingkan bahasa tubuh, masyarakat, budaya, ekonomi dan politik nasional serta mendahulukan kepentingan nasional (Hasan, 2012; Rosala \& Budiman, 2020). Sub nilai nasionalisme meliputi penghargaan terhadap budaya bangsa sendiri, pemeliharaan kekayaan budaya bangsa, rela berkorban, berani mengungguli, berprestasi, cinta tanah air, peduli lingkungan, taat hukum, menghargai keragaman budaya, suku dan agama (Marshel \& Ratnawulan, 2020; Stupar-Rutenfrans et al., 2021). Nilai kepribadian mandiri adalah sikap dan perilaku. Mengandalkan orang lain dan menggunakan semua energi, pikiran. Saatnya mewujudkan harapan, impian dan cita-cita. Sub nilai mandiri meliputi etika profesi (kerja keras), keuletan ketekunan, efektivitas tempur, profesionalisme, kreativitas, keberanian, dan kehadiran pembelajaran seumur hidup. Nilai karakter gotong royong mencerminkan perilaku hormat dan semangat gotong royong untuk memecahkan masalah Bersama (Y. Ningsih, 2018; Widodo, 2020). Nilai-nilai pada diri manusia dapat dilihat dari tingkah-laku. Berdasarkan analisis tersebut, pendidikan merupakan jalan pertama untuk membentuk sikap bangsa. Pengetahuan sikap bangsa melihat dari pengetahuan dapat dicapai dengan memasukkan penilaian sikap ke dalam pelajaran yang diberikan di sekolah (Thoyyibah et al., 2019; Zaini \& Dewi, 2017).

\section{SIMPULAN}

Integrasi dalam pembentukan karakter melalui pembelajaran PKn dapat menjadi salah satu strategi pada pembentukan. Dalam pendidikan tidak hanya dengan materi pendidikan yang mesti ditanamkan tetapi harus adanya upaya karakter yang terbentuk dari peserta didik, agar dapat memiliki kesempirnaan tujuan pendidikan yang utuh. Sudah semestinya pendidikan melahirkan jiwa yang tangguh dalam segala aspek pengetahuan serta tangung jawab yang dimiliki individu. Penulis berharap dengan adanya penelitian ini dapat menjadi acuan untuk peneliti selanjutnya.

\section{DAFTAR PUSTAKA}

Agnies zka Bates. (2019). Character education and the 'priority of recognition. Cambrid Ge Journal of Educatio N, 49(6), 695-710. https://doi.org/10.1080/0305764X.2019.1590529.

Alsabahi, M. A., Maisurah, K., Bahador, K., \& Saat, R. M. (2021). Cogent Business \& Management The influence of personal characteristics and workplace learning on information technology competency among external 
auditors : The role of organisational culture as a moderator The influence of personal characteristics and wo. Cogent Business \& Management, 8(1). https://doi.org/10.1080/23311975.2021.1899625.

Baehaqi, M. L. (2020). Strengthening Discipline Character of Students at Muhammadiyah Boarding-School ( MBS ) Muhiba Yogyakarta. Dinamika Ilmu, 20(1), 63-82. https://doi.org/10.21093/di.v20i1.1671.

Birhan, W., Shiferaw, G., \& Tiruye, A. A. M. T. H. (2021). Exploring the context of teaching character education to children in preprimary and primary schools. Social Sciences \& Humanities Open, 4(1), 100171. https://doi.org/10.1016/j.ssaho.2021.100171.

Buchori, Rahmawati, S., \& Wardani, S. (2017). The Development of A Learning Media for Visualizing the Pancasila Values Based on Information and Communication Technology. Jurnal Cakrawala Pendidikan, 36(3), 502521. https://doi.org/10.21831/cp.v36i3.12748.

Budiwibowo, S. (2016). Membangun Pendidikan Karakter Generasi Muda Melalui Budaya Kearifan Lokal Di Era Global. Premiere Educandum: Jurnal Pendidikan Dasar Dan Pembelajaran, 3(01), 39-49. https://doi.org/10.25273/pe.v3i01.57.

Cahyaningrum, E. S., Sudaryanti, S., \& Purwanto, N. A. (2017). Pengembangan Nilai-Nilai Karakter Anak Usia Dini Melalui Pembiasaan Dan Keteladanan. Jurnal Pendidikan Anak, 6(2), 203-213. https://doi.org/10.21831/jpa.v6i2.17707.

Dalmeri, Gea, A., \& Antonius. (2015). Toward Peace-Loving Attitude Trough Education Character Dalmeri \& Antonius Atosokhi Gea Indraprasta PGRI University and Binus University Jakarta. Al-Ulum: Jurnal Studi Islam, 15(2), 479-496. https://doi.org/10.30603/au.v15i2.213.

Dewi, Asri, \& Suniasih. (2019). Pengaruh Model Quantum Teaching Berbasis Tri Hita Karana Terhadap Kompetensi Pengetahuan Ppkn Siswa Kelas V. Jurnal Pendidikan Multikultural Indonesia, 2(1), 33-34. https://doi.org/10.23887/jpmu.v2i1.20790.

Dewi, N. L., Dantes, N., \& Sadia, I. W. (2013). Pengaruh Model Pembelajaran Inkuiri Terbimbing Terhadap Sikap Ilmiah dan Hasil Belajar IPA. Jurnal Pendidikan Dasar Ganesha, 3(1). https://doi.org/10.19184/jpf.v6i2.5020.

Erliani, S. (2017). Peran Gerakan Pramuka Untuk Membentuk Karakter Kepedulian Sosial dan Kemandirian (Studi Kasus di SDIT Ukhwah dan MIS An-Nuriyyah 2 Banjarmasin). Jurnal Ilmiah Pendidikan Guru Madrasah Ibtidaiyah, VII(1). https://doi.org/10.18592/aladzkapgmi.v7i1.2020.

Farisia, H. (2016). Integrasi Nilai-Nilai Pancasila dan Civic Education Dalam Buku Temtik Kurikulum 2013 (Edisi Revisi 2016). Jurnal Handayani, 8(1), 1-10. https://doi.org/https://doi.org/10.24114/jh.v8i1.10561.

Genc, M., Genc, T., \& Rasgele, P. G. (2018). Effects of nature-based environmental education on the attitudes of 7 th grade students towards the environment and living organisms and affective tendency. International Research in Geographical and Environmental Education, 27(4), 326-340. https://doi.org/10.1080/10382046.2017.1382211.

Ghufron, A. (2010). Integrasi Nilai-Nilai Karakter Bangsa Pada Kegiatan Pembelajaran. Jurnal Cakrawala Pendidikan, 1(3), 13-24. https://doi.org/10.21831/cp.v1i3.230.

Gönültaş, S., Richardson, C. B., \& Mulvey, K. L. (2021). But they weren't being careful! Role of theory of mind in moral judgments about victim and transgressor negligence. Journal of Experimental Child Psychology, 212. https://doi.org/10.1016/j.jecp.2021.105234.

Hafeez, M., Tahira, F., Kazmi, Q. A., \& Zahid, M. (2020). Analysis of moral reasoning of teachers and the students with respect to Kohlberg's theory of moral development. International Journal of Business Strategy and Social Sciences, http://www.sciencepublishinggroup.com/journal/paperinfo?journalid=391\&doi=10.11648/j.ijnpt.2020 0601.12.

Hasan, S. H. (2012). Pendidikan Sejarah Untuk Memperkuat Pendidikan Karakter. Paramita: Historical Studies Journal, 22(1). https://doi.org/10.15294/paramita.v22i1.1875.

Iannuccilli, M., Dunfield, K. A., \& Byers-Heinlein, K. (2021). Bilingual children judge moral, social, and language violations as less transgressive than monolingual children. Journal of Experimental Child Psychology, 208. https://doi.org/10.1016/j.jecp.2021.105130.

Ikhsan, M. A. (2017). Nilai - Nilai Cinta Tanah Air Dalam Perspektif Al-Qur'an. Jurnal Ilmiah Pendidikan Pancasila Dan Kewarganegaraan, 2(2), 108-114. https://doi.org/10.17977/um019v2i22017p108.

Inanna. (2013). Peran Pendidikan Karakter Dalam Mengembangkan Kecerdasan Moral. Jurnal Pendidikan Karakter, Vol 1(1), 27-33. https://doi.org/10.21831/jpk.v0i1.1287.

Juneman, Meinarno, E. A., \& Rahardjo, W. (2012). Symbolic Meaning of Money, Self-esteem, and Identification with Pancasila Values. Procedia - Social and Behavioral Sciences, 65. https://doi.org/10.1016/j.sbspro.2012.11.099.

Khaironi, M. (2017). Pendidikan Moral Pada Anak Usia Dini. Jurnal Golden Age, 1(01), 1. https://doi.org/10.29408/goldenage.v1i01.479.

Khoiri, A., Agussuryani, Q., \& Hartini, P. (2017). Penumbuhan Karakter Islami melalui Pembelajaran Fisika Berbasis Integrasi Sains-Islam. In Tadris: Jurnal Keguruan dan Ilmu Tarbiyah (Vol. 2, Issue 1, p. 19). 
https://doi.org/10.24042/tadris.v2i1.1735.

Lewis, M., \& Ponzio, V. (2016). Character Education As the Primary Purpose of Schooling for the Future. Jurnal Ilmiah Peuradeun, 4(2), 137. https://doi.org/10.26811/peuradeun.v4i2.92.

Liang, Q., Torre, J. de la, \& Law, N. (2021). Do background characteristics matter in Children's mastery of digital literacy? A cognitive diagnosis model analysis. Computers in Human Behavior, 122. https://doi.org/10.1016/j.chb.2021.106850.

Ma, H. Y., Kao, J. C., Kao, R. H., \& Cho, C. C. (2020). How to shape the employees' sustainable work attitude: The moderating effect of supervisor attitudes. Sustainability (Switzerland), 12(20), 1-27. https://doi.org/10.3390/su12208331.

Marhayani, D. A. (2016). Development of Character Education Based on Local Wisdom in Indegenous People Tengahan Sedangagung. JETL (Journal Of Education, Teaching and Learning), 1(2), 66. https://doi.org/10.26737/jetl.v1i2.40.

Marshel, J., \& Ratnawulan. (2020). Analysis of Students Worksheet (LKPD) integrated science with the theme of the motion in life using integrated connected type 21st century learning. Journal of Physics: Conference Series, 1481(1). https://doi.org/10.1088/1742-6596/1481/1/012046.

Maulida, I., Dibia, I. K., \& Astawan, I. G. (2020). The Development of Social Attitude Assessment Instrument and Social Studies Learning Outcomes Grade IV on Theme of Indahnya Keragaman di Negeriku. Indonesian Journal Of Educational Research and Review, 3(1), 12. https://doi.org/10.23887/ijerr.v3i2.25823.

Mediatati, N., \& Suryaningsih, I. (2017). Penggunaan Model Pembelajaran Course Review Horay Dengan Media Flipchart Sebagai Upaya Meningkatkan Hasil Belajar PKn. Jurnal Ilmiah Sekolah Dasar, 1(2). https://doi.org/10.23887/jisd.v1i2.10146.

Muhtar, T., \& Dallyono, R. (2020). Character Education From the Perspectives of Elementary School Physical Education Teachers. Jurnal Cakrawala Pendidikan, 39(2), 395-408. https://doi.org/10.21831/cp.v39i2.30647.

Mustofa, R., \& Syafi'ah, R. (2018). Pengembangan Media Pembelajaran Pop Up Book Materi Kenampakan Permukaan Bumi Mata Pelajaran IPA Kelas III SD. ELSE (Elementary School Education Journal), 2, 30-41. https://doi.org/http://dx.doi.org/10.30651/else.v2i2.1723.

Ningsih, D. P., \& Maulida, I. (2019). Implementasi Kurikulum 2013 Dalam Membentuk Karakter Siswa Pada Pembelajaran Tematik Integratif Kelas IV di SDN I Gapuk. Jurnal Pendidikan, 3(1). https://doi.org/http://dx.doi.org/10.36312/jisip.v3i1.988.

Ningsih, Y. (2018). Penilaian Sikap Sosial Pada Anak Berkebutuhan Khusus Di Slb Negeri 2 Yogyakarta. Jurnal Bimbingan Dan Konseling Islam, 08(02), 208-215. https://doi.org/10.29080\%2Fjbki.v8i2.85.

Nordlöf, C., Hallström, J., \& Höst, G. E. (2019). Self-efficacy or context dependency?: Exploring teachers' perceptions of and attitudes towards technology education. International Journal of Technology and Design Education, 29(1), 123-141. https://doi.org/10.1007/s10798-017-9431-2.

Novianti, N. (2017). Teaching character education to college students using bildungsromans. International Journal of Instruction, 10(4), 255-272. https://doi.org/10.12973/iji.2017.10415a.

Nugrahani, F. (1386). The Development Of Film Based Literary Materials Which Suport Character Education. Jurnal Cakrawala Pendas, XXXVI(3), 472-486. https://doi.org/10.21831/cp.v36i3.14219.

Octavia, B. (2020). Kasus Korupsi Bansos Corona Yang Melibatkan Menteri Sosial Ditinjau Dari Moral Keutamaan. Journal of Chemical Information and Modeling, 53(9), 1689-1699. https://doi.org/10.31219/osf.io/cdujz.

Öztürk, M., Akkan, Y., \& Kaplan, A. (2020). Reading comprehension, Mathematics self-efficacy perception, and Mathematics attitude as correlates of students' non-routine Mathematics problem-solving skills in Turkey. International Journal of Mathematical Education in Science and Technology, 51(7), 1042-1058. https://doi.org/10.1080/0020739X.2019.1648893.

Panagopoulos, N. G., Hochstein, B., Baker, T. L., \& Pimentel, M. A. (2018). Boosting sales force morale in highly dynamic, complex markets: The role of job resources. Industrial Marketing Management, 74(12), 237253. https://doi.org/10.1016/j.indmarman.2018.06.001.

Pane, M. M., \& Rina Patriana. (2016). The Significance of Environmental Contents in Character Education for Quality of Life. Procedia - Social and Behavioral Sciences, 222, $244-252$. https://doi.org/10.1016/j.sbspro.2016.05.153.

Pebriana, P. H. (2017). Analisis Kemampuan Berbahasa dan Penanaman Moral pada Anak Usia Dini melalui Metode Mendongeng. Jurnal Obsesi: Journal of Early Childhood Education, 1(2). https://doi.org/10.31004/obsesi.v1i2.34.

Prasetyo, G., Hidayatullah, M. F., Akhyar, M., Wiranto, \& Perdana, R. (2020). Strengthening Students' Character Through Multimedia Learning In Primary Schools Education: Systematic LiteraturPrasetyo, G., Hidayatullah, M. F., Akhyar, M., Wiranto, \& Perdana, R. (2020). Strengthening Students' Character Through Multimedia Learning In . Humanities \& Social Sciences Reviews, 8(3), 268-277. https://doi.org/10.18510/hssr.2020.8328.

Pratama, F. I. P., Kristiyanto, A., \& Widyastono, H. (2021). Character Values of Third Grade Slow Learner in 
Character Education at the Inclusive Elementary School. JPI, 10(2), 345-352. https://doi.org/10.23887/jpi-undiksha.v10i2.28838.

Putrayasa, I. B. (2017). Literature as Media Education Nation Character Values. International Journal of Linguistics, Literature, and Culture, 3(3), 1-9. https://doi.org/10.21744/ijllc.v3i3.443.

Putri, M. A. (2018). Relevankah Pancasila dan Globalisasi? Mengungkap Hubungan Pancasila dan Indentitas Global. Jurnal Ilmiah Pendidikan Pancasila Dan Kewarganegaraan, 3(1), 74-80. https://doi.org/10.17977/um019v3i12018p074.

Ramdan, A. Y., \& Fauziah, P. Y. (2019). Peran orang tua dan guru dalam mengembangkan nilai-nilai karakter anak usia sekolah dasar. Jurnal Pendidikan Dasar Dan Pembelajaran, 9(2), 100. https://doi.org/10.25273/pe.v9i2.4501.

Rosala, D., \& Budiman, A. (2020). Local Wisdom-based Dance Learning: Teaching Characters to Children through Movements. Mimbar Sekolah Dasar, 7(3), 304-326. https://doi.org/10.17509/mimbar-sd.v7i3.28185.

Safitri, N., Kuswanto, C. W., \& Alamsyah. (2019). Metode Penanaman Nilai-Nilai dan Moral Agam Anak Usia Dini. Journal of Early Childhood Education, 1(2), 29-44. https://doi.org/10.15408/jece.v1i2.13312.

Sakaningsih, Asri, \& Negara. (2014). Model Pembelajaran Creative Problem Solving Berbasis Reinforcement Berpengaruh Terhadap Hasil Belajar PKn siswa kelas V SD N 18 Dangin Puri. Mimbar PGSD Undiksha, 2(1). https://doi.org/10.23887/jjpgsd.v2i1.3030.

Singh, B. (2019). Character education in the 21st century. Journal of Social Studies (JSS), 15(1), 1-12. https://doi.org/10.21831/jss.v15i1.25226.

Sriyanto, Leksono, \& Harwanto. (2019). Bahan Ajar PPKn Berbasis Karakter dan Literasi Untuk Siswa Kelas IX SMP Al Hikmah Surabaya. Edmotech, 4(2), 130-142. https://doi.org/10.17977/um039v4i22019p130.

Stupar-Rutenfrans, S., Verdouw, P. C. D., Boven, J. van, \& Ryzhkina, O. A. (2021). Ethnic outgroup aggression: A pilot study on the importance of emotion regulation, nationalism and susceptibility to persuasion. International Journal of Intercultural Relations, 84. https://doi.org/https://doi.org/10.1016/j.ijintrel.2021.07.004.

Sudaryanti, D., Sukoharsono, E. G., Baridwan, Z., \& Mulawarman, A. D. (2015). Critical Analysis on Accounting Information Based On Pancasila Value. Procedia - Social and Behavioral Sciences, 172. https://doi.org/10.1016/j.sbspro.2015.01.399.

Supardi. (2010). Pegaruh Konsep Diri, Sikap Siswa Pada Matematika Dan Kecemasan Siswa Terhadap Hasil Belajar Matematika. Cakrawala Pendidikan, 3(1). https://doi.org/10.21831/cp.v3i3.362.

Suprihatin. (2017). Penggunaan Media Pengajaran Untuk Meningkatkan Prestasi Belajar Mata Pelajaran PPKn Pada Siswa Kelas X Semester I Smk Negeri 1 Bendo Kecamatan Bendo Kabupaten Magetan Tahun Ajaran 2014/2015. Citizenship: Jurnal Pendidikan Pancasila Dan Kewarganegaraan, 3(2). https://doi.org/10.25273/citizenship.v3i2.1259.

Suryawati, E., \& Osman, K. (2018). Contextual learning: Innovative approach towards the development of students' scientific attitude and natural science performance. Eurasia Journal of Mathematics, Science and Technology Education, 14(1), 61-76. https://doi.org/10.12973/ejmste/79329.

Suwartini, S. (2017). Pendidikan Karakter dan Pembangunan Sumber Daya Manusia Keberlanjutan. Trihayu: Jurnal Pendidikan Ke SD An, 4(1), 220-234. https://doi.org/10.30738/trihayu.v4i1.2119.

Thoyyibah, N., Hartono, R., \& Bharati, D. A. L. (2019). The Implementation of Character Education in the English Teaching Learning Using 2013 Curriculum. English Education Journal, 9(2), 254-266. https://doi.org/10.15294/eej.v9i2.30058.

Widodo, A. (2020). Nilai Budaya Ritual Perang Topat Sebagai Sumber Pembelajaran IPS Berbasis Kearifan Lokal di Sekolah Dasar. Gulawentah:Jurnal Studi Sosial, $\quad 5(1), \quad 1$. https://doi.org/10.25273/gulawentah.v5i1.6359.

Winther-Lindqvist, D. A. (2020). Caring well for children in ECEC from a wholeness approach - The role of moral imagination. Learning, Culture and Social Interaction, 1. https://doi.org/10.1016/j.lcsi.2020.100452.

Zahro, M., Sumardi, \& Marjono. (2017). The Implementation Of The Character Education In History Teaching. Jurnal Historica, 1(2252), 1-11. https://jurnal.unej.ac.id/index.php/JHIS/article/view/5095.

Zaini, H., \& Dewi, K. (2017). Pentingnya Media Pembelajaran Untuk Anak Usia Dini. Raudhatul Athfal: Jurnal Pendidikan Islam Anak Usia Dini, 1(1). https://doi.org/10.19109/ra.v1i1.1489. 